\title{
Grain Growth and Grain Boundary Wetting Phase Transitions in the Al-Ga and Al-Sn-Ga Alloys of High Purity
}

\author{
B. Straumal*,***, S. Risser*,**, V. Sursaeva***, B. Chenal ${ }^{* *}$ and W. Gust* \\ * Max-Planck-Institut für Metallforschung and Institut für Metallkunde, Seestrasse 75, 7000 Stuttgart 1, \\ Germany \\ ** Pechiney CRV, Centre de Recherches de Voreppe, BP. 27, 38340 Voreppe, France \\ *** Institute of Solid State Physics, Russian Academy of Sciences, 142432 Chernogolovka, Moscow \\ district, Russia
}

\begin{abstract}
Grain growth was studied in high purity Al-Ga alloys with $\mathrm{Ga}$ contents of $0.001,0.005$ and I $\mathrm{wt} \%$. The transition from normal to abnormal grain growth was investigated in dependence on Ga content and temperature. The orientations of individual grains were determined with aid of the selected area channelling method in the contact area between the abnormally growing large grains and normal matrix. The grain boundary wetting phase transitions were also studied in $\mathrm{Al}-\mathrm{Sn}$ and $\mathrm{Al}-\mathrm{Sn}-\mathrm{Ga}$ alloys.
\end{abstract}

\section{INTRODUCTION}

In the last decade $\mathrm{Al}$ and $\mathrm{Al}$ alloys of very high purity have begun to play a very important role as materials for wide industrial use. The most important examples are foils of high purity for capacitors and anodized products which are produced by rolling or extruding mainly for building and reflector applications. The quality of these products depends critically on the uniformity of their grain structure. The formation of very large grains or a large scatter of grain sizes in a material can induce a non-uniform deformation and recrystallization texture and, therefore, can cause intolerable shape fluctuations of the end product. Therefore, heterogeneous grain structure formation at any step of the aluminium transformation, from homogenizing to intermediate annealing or coating makes the metal unacceptable. Our preliminary studies show that the uniformity of the grain structure of high purity Al depends critically on the small (about $10^{-3}$ wt.\%) additions of other elements.

The main goal of this work was to discover the reasons for this influence. According to our preliminary experiments, the most pronounced non-uniformity of grain structure in high purity $\mathrm{Al}$ is induced by $\mathrm{Ga}$ additions. Therefore, the influence of $\mathrm{Ga}$ on the grain growth and grain boundary wetting in $\mathrm{Al}$ were studied.

\section{EXPERIMENTAL}

The base metal in our studies was $5 \mathrm{~N}(99.999 \mathrm{wt} . \%) \mathrm{Al}$. Three Al-Ga alloys containing $0.001,0.005$ and 1 wt.\% of Ga were produced from this $5 \mathrm{~N} \mathrm{Al}$ and $5 \mathrm{~N} \mathrm{Ga}$ as ingots with a weight of about $7 \mathrm{~kg}$. The Ga content in the most concentrated alloy lies well below the Ga solubility in the Al based solid solution (18 wt. $\%$ at $0^{\circ} \mathrm{C}$ and $10 \mathrm{wt} . \%$ at $\left.450^{\circ} \mathrm{C}[1]\right)$. This fact and the high purity of the alloy components exclude the formation of any bulk precipitates which can influence the grain growth in the temperature interval studied. The foundry state products are cut out, homogenized $\left(30 \mathrm{~h}\right.$ at $\left.570^{\circ} \mathrm{C}\right)$, machined and cold rolled to thickness $2.5 \mathrm{~mm}$ with reduction of $60 \%$ and a high number of passes (over 20). During the rolling the plates are periodically cooled in liquid nitrogen in order to conserve their temperature below about $-10^{\circ} \mathrm{C}$ and to prevent recrystallization. The cold rolled bands were annealed at $450^{\circ} \mathrm{C}$ for $5 \mathrm{~min}$ in order to have a fully recrystallized structure without a deformed matrix (with a mean grain size of 200 to $500 \mu \mathrm{m}$ ). 
The recrystallized bands were cut into pieces with dimensions about $4 \times 5 \mathrm{~cm}$. These pieces were then annealed in an air furnace at the temperatures of $350,380,405$ and $425^{\circ} \mathrm{C}$. Each specimen was annealed several times at the same temperature. After each break the sample was etched for 1-2 min in a solution of $10 \mathrm{ml} \mathrm{HCl}, 50 \mathrm{ml} \mathrm{HNO}_{3}$ and $50 \mathrm{ml} \mathrm{HCl}$ in order to reveal the grain structure. The microstructure was photographed and the mean grain size $d$ was determined on $400-500$ grains with aid of the intersection method using optical microscopy. The measurements were repeated after each new anneal in the same area in order to diminish the influence of the difference of starting grain size in the areas.

One sample was specially prepared for the investigation of the onset of secondary recrystallization. In this sample annealed at $380^{\circ} \mathrm{C}$ for $18 \mathrm{~h}$ the fine grain structure typical for normal grain growth was still present together with the large abnormal grains. Specimens $3 \mathrm{~mm}$ wide and $10 \mathrm{~mm}$ long were then cut from this sample in order to investigate their microstructure with aid of the selected area channelling (SAC) technique [2]. The SAC technique was used in order to determine the orientations (a) of the small "normal" grains in the recrystallized matrix and (b) of the large abnormal grains. In the SAC technique all grains can be seen and the misorientations can be determined in the actual image [3]. It means that many grains can be analysed, and the overall picture of the misorientation distribution can quickly be obtained. The orientations of the grains were measured "by hand" from a channelling pattern. A grain orientation can be obtained from a screen using only a ruler and standard map. This method was adopted as a simple computer program for routine orientation measurements. It requires the operator to identify poles in the channelling pattern. Then the screen coordinates of three points on each of two pairs of lines and of one pole are then input into the computer program. These data are compared with a reference table of rotations and interplanar spacings (band widths) in order to index these lines and thus solve the pattern. The orientation of a grain with respect to the specimen frame may be equally described both by rotation angles and rotation axis or by proper orthogonal matrices. The direction cosines for the zone axis and for axis perpendicular to channelling planes were determined by a primary processing of the patterns. Those with respect to grain frame were obtained via an indexing procedure. In this work the channelling patterns and image were analysed together. In this case the orientations can be ascribed to individual grains and related to both microscopic and macroscopic features of the specimen.

For the wetting experiments the bicrystal with tilt [011] with misorientation angle $38.5^{\circ}$ was produced from $5 \mathrm{~N}$ Al using a modified Bridgman technique [4]. The samples were then covered with a $\mathrm{Sn}-3.3 \mathrm{wt} . \%$ Ga layer. For this purpose the Al bicrystals were etched for $40-60 \mathrm{~s}$ with the solution mentioned above and brought in contact with a liquid $\mathrm{Sn}-3.3 \mathrm{wt} . \% \mathrm{Ga}$ alloy made of constituents having $99.9999 \mathrm{wt} \%$ purity at about $240^{\circ} \mathrm{C}$ in an atmosphere of pure argon. The surface layer at the end of the bicrystal dissolves in the liquid metal and saturates the melt up to the liquidus concentration. The contact between the melt and the $\mathrm{Al}$ bicrystal forms within a few seconds. The samples annealed were 2-3 mm long with $\mathrm{Sn}(\mathrm{Ga})$ layers $0.2-$ $0.4 \mathrm{~mm}$ thick. All individual samples were cut from the same bicrystal. The coated bicrystalline samples were placed together with an oxygen getter (a piece of a Ta foil) in evacuated silica capsules with a residual pressure of $410^{-4} \mathrm{~Pa}$. Each sample was annealed at a prescribed temperature maintained constant within $0.2^{\circ} \mathrm{C}$ for $20 \mathrm{~min}$ and subsequently quenched in water with a cooling rate of $10^{2} \mathrm{~K} / \mathrm{s}$. After quenching the samples were embedded in a supporting medium and then mechanically ground and polished to make a polished surface parallel to the $\{011\}$ surface of the Al bicrystal and perpendicular to the GB and solid/liquid interface. The polished surface was etched for a few seconds in a 5\% aqueous solution of HF. The contact area between the GB and the interphase boundary was photographed in an optical microscope with a magnification of $1000: 1$, and the contact angle $\theta$ was measured.

\section{RESULTS}

At the beginning of grain growth anneals the samples have the "starting" microstructure after the recrystallization annealing of $5 \mathrm{~min}$ at $450^{\circ} \mathrm{C}$. This microstructure varies according to the alloys. The microstructure of $5 \mathrm{~N} \mathrm{Al}$ and alloys containing $0.001,0.005 \mathrm{wt} . \% \mathrm{Ga}$ was homogeneous and it is easy to determine the mean grain size of the new recrystallized grains, which generally is around $500 \mu \mathrm{m}$. In 


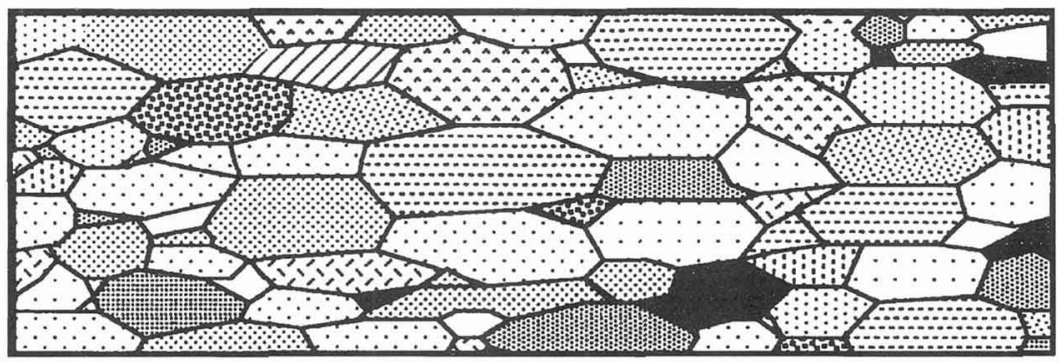

a)

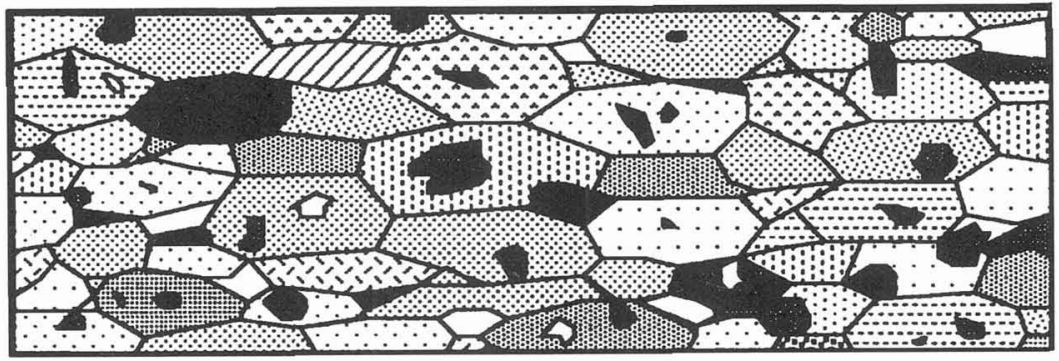

b)

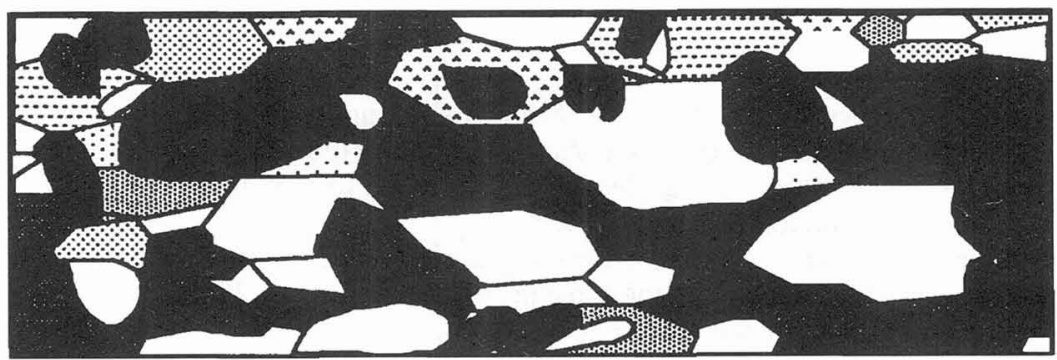

c)

Figure 1: Scheme of the evolution of the microstructure during the transition from normal to abnormal grain growth in the $\mathrm{Al}-1 \mathrm{wt}$ \% Ga alloy

contrast, the microstructure of the $\mathrm{A} 1-1 \mathrm{wt} . \% \mathrm{Ga}$ is very heterogeneous (Fig. 1a). The recrystallization occurs inside the old grains of the matrix and, therefore, the outline of the old grains can still be seen. Consequently, the recrystallized new grains are homogeneous in each old grain but strongly differ strongly between the different old grains (grain size $200-800 \mu \mathrm{m}$ ). A recrystallization annealing at $480^{\circ} \mathrm{C}$, a higher temperature, does not eliminate any more of this old cold-rolled structure.

Figure 1 displays the evolution of the microstructure of the recrystallized samples during grain growth. The most important feature of grain growth in pure $\mathrm{Al}$ and the $\mathrm{Al}$ alloys studied is the transition from normal to abnormal grain growth. After the beginning of the anneal the grain structure is uniform and the scatter of grain sizes is low. 


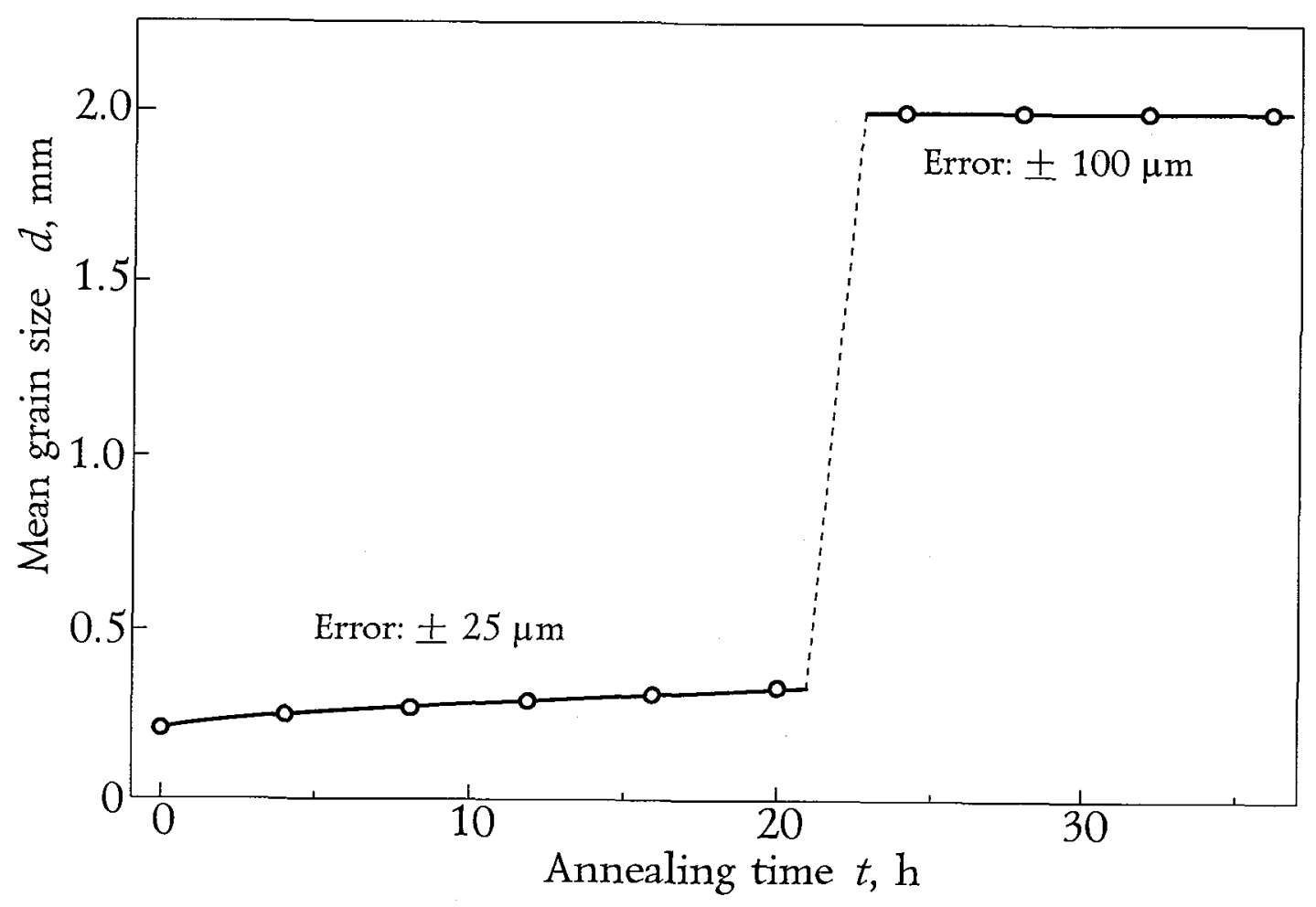

Figure 2: The dependence of mean grain size $d$ on annealing time $t$ for Al-1wt.\%Ga alloy at $380^{\circ} \mathrm{C}$

Fig. 1 shows schematically the three stages of this abnormal grain growth in the Al-1wt.\% Ga alloy:

- a) The recrystallized microstructure does not obliterate all the cold-rolled microstructure, and the new recrystallized grains are homogeneous inside an old grain of the former matrix, but their mean grain size varies a lot from one old grain to another.

- b) The new recrystallized grains grow inside the old grains. Growth is faster for some of them and some big new grains appear, which have often the same profile as the former old grain.

- c) Very big grains cover most of the sample surface. They have grown inside the old grains and have, most of the time, the same profile and size. It is also possible that they grow inside other old grains.

Figure 2 displays the dependence of mean grain size $d$ on annealing time $t$ for $\mathrm{Al}-1 \mathrm{wt} . \% \mathrm{Ga}$ at $380^{\circ} \mathrm{C}$. The average error is $25 \mu \mathrm{m}$. The error bars have purposely not been shown on the graph in order to keep the graph clear and not overloaded. On the whole, the estimated error is $25 \mathrm{~mm}$ unless stated otherwise. At the first stage $d$ increases with $t$ slowly. Between 20 and $24 \mathrm{~h}$ the sudden increase of $d$ proceeds from 0.3 to $2 \mathrm{~mm}$. (For the large abnormal grains the average error is $0.1 \mathrm{~mm}$ ). Later $d$ practically does not increase with temperature.

In figure 3 the $d(t)$ dependencies are shown for $5 \mathrm{~N} \mathrm{Al}$ and three $\mathrm{Al}-\mathrm{Ga}$ alloys for four different temperatures. At $350^{\circ} \mathrm{C}$ only normal grain growth occurs. The grains growing abnormally fast do not appear even after $720 \mathrm{~h}$ (this point is not shown in the figure). The equiaxial grains grow uniformly. The growth rate diminishes with $t$. Grain growth follows a square root of time law during the first $20 \mathrm{~h}$ of annealing, then progressively moves away and almost equals zero after $100 \mathrm{~h}$. The fastest grain growth occurs in the pure metal. The alloys containing 0.001 or $0.005 \mathrm{wt} . \%$ of $\mathrm{Ga}$ grow slower and reach a mean grain size which is slightly below that of $5 \mathrm{~N}$ Al. The mean grain size of the alloy containing $0.005 \mathrm{wt} \% \mathrm{Ga}$ is larger than the value for 0.005 wt.\% doping. Grain growth is clearly slowed down in 


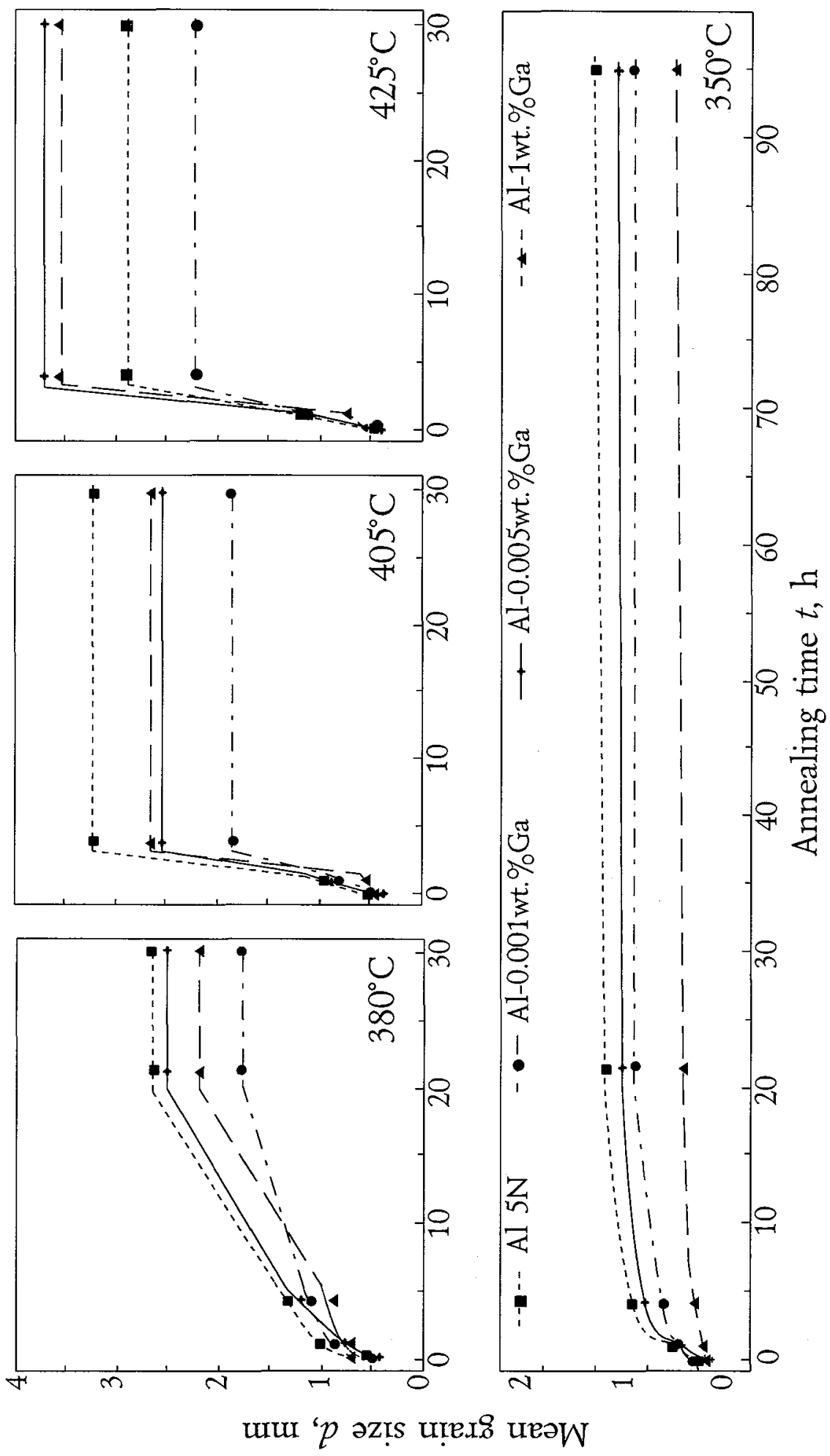

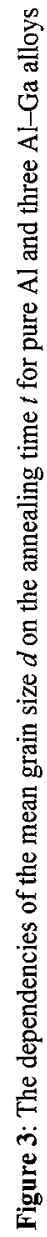




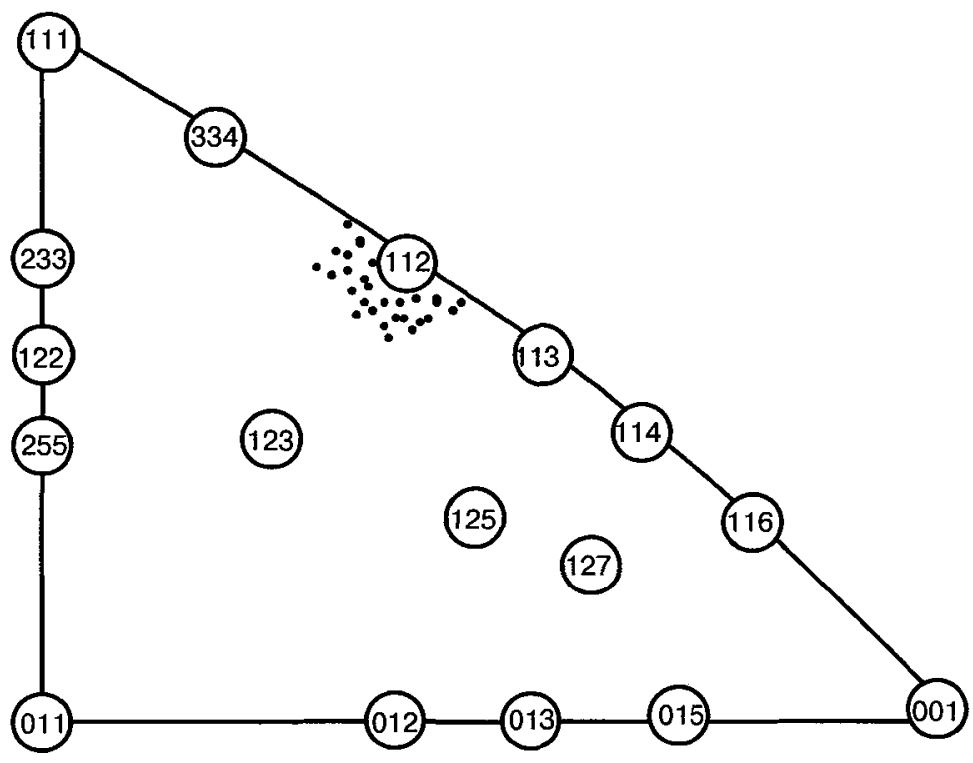

a)

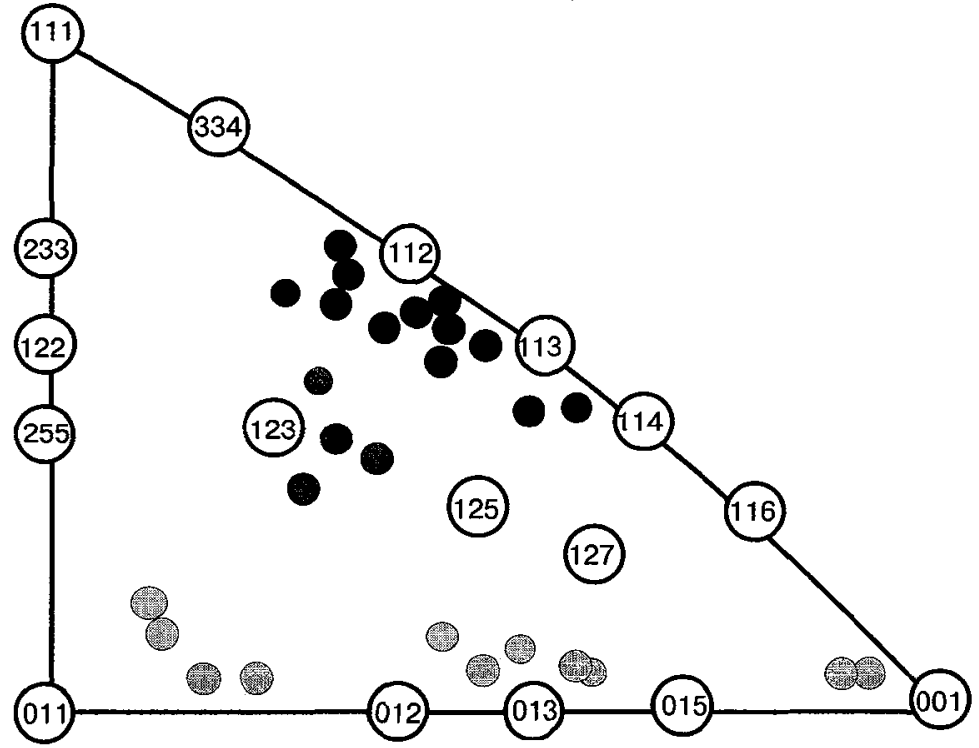

b)

Figure 4: Inverse pole figures of grain normals in the Al-1wt.\%Ga alloy at the transition from normal to abnormal grain growth $\left(380^{\circ} \mathrm{C}\right.$ for $18 \mathrm{~h}$ ) (a) for the small grains in the fine grain matrix formed after normal grain growth and (b) for the large grains formed after the beginning of abnormal grain growth 


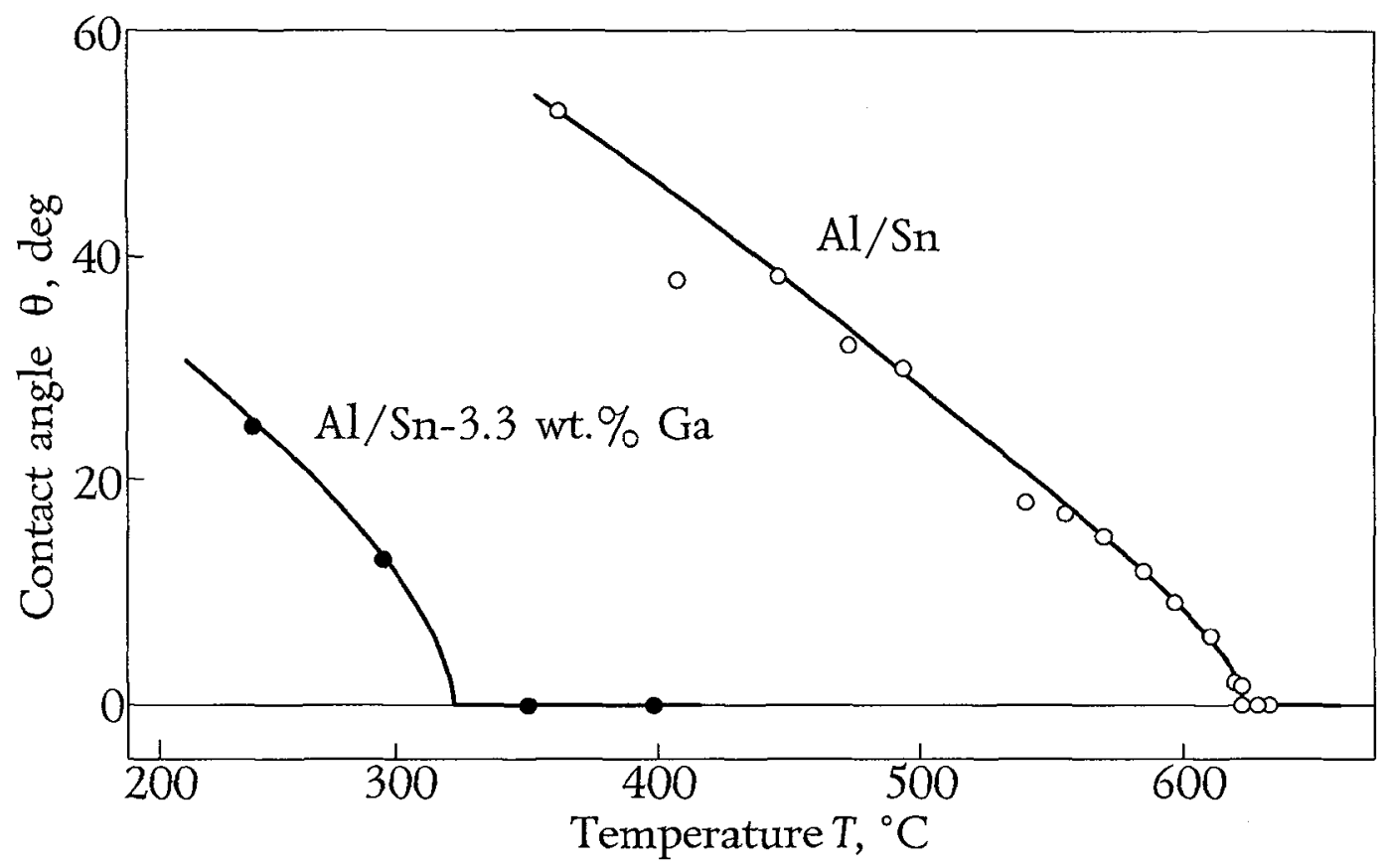

Figure 5: The temperature dependence of the contact angle $\theta$

Al- 1 wt. \% Ga. These results are in line with the theory on the influence of the impurity drag on the grain growth. The impurity atoms are supposed to slow down the grain growth.

At higher temperatures we observe a sudden and strong grain growth after the stage of normal grain growth. Mean grain size is now about $2-3 \mathrm{~mm}$ and some grains have a diameter larger than $5 \mathrm{~mm}$. Between 10 and $20 \mathrm{~h}$ of annealing at $380^{\circ} \mathrm{C}$ an acceleration of the grain growth is observed. This phenomenon is weak in $\mathrm{Al}-0.001 \mathrm{wt} \% \mathrm{Ga}$, increased in pure $\mathrm{Al}$ and $\mathrm{Al}-0.005 \mathrm{wt} . \% \mathrm{Ga}$, and very strong in $\mathrm{Al}-1 \mathrm{wt} . \%$ $\mathrm{Ga}$. The shape of the curve is so modified that we have to call it abnormal growth. After $20 \mathrm{~h}$ of annealing, the grains do not grow any further for an annealing time of $70 \mathrm{~h}$. This abnormal growth does not only occur in A $1-\mathrm{Ga}$ alloys but also in $5 \mathrm{~N} \mathrm{A1}$, whose mean grain size is still larger in comparison with the Al-Ga alloys. In all the samples, some recrystallized grains grow abnormally fast and "eat" the recrystallized grains of the neighbourhood.

The higher the temperature of annealing, the faster the grain growth and the larger the mean grain size. At 405 and $425^{\circ} \mathrm{C}$ this abnormal grain growth is so strong that af ter several hours stagnation is reached. Whereas during the first hour of annealing the mean grain size grows from 500 up to $800 \mu \mathrm{m}$, during the next three hours it grows from $800 \mu \mathrm{m}$ up to $3 \mathrm{~mm}$. The abnormal grain growth occurs during this period of annealing and the phenomenon is stronger and earlier than at $380^{\circ} \mathrm{C}$. The same behaviour is observed in the pure metal and in alloys containing 0.001 or $0.005 \mathrm{wt} . \%$ of $\mathrm{Ga}$.

Figure 4 displays the inverse pole figures of the grain normals in the sample where the fine grained matrix formed during the normal grain growth coexists with the large grains grown abnormally fast. These plots contain the information about the crystallographic planes which are parallel to the surface of the sample. All fine grains have an orientation close to (112). The abnormal grains can be divided into threc groups:

- Grains with orientations close to (112) shown with black symbols;

- Grains with orientations close to (123) shown with dark-grey symbols;

- Grains with orientations between (011) and (001) shown with grey symbols. 
Figure 5 displays the temperature dependencies of the contact angle $\theta$ at the intersection of the grain boundary in $\mathrm{Al}$ with the solid/liquid interface for the $\mathrm{Al} / \mathrm{Sn} \mathrm{[4]} \mathrm{and} \mathrm{Al/Sn-3.3} \mathrm{wt. \%} \mathrm{Ga} \mathrm{systems.} \mathrm{The}$ contact angle decreases in both cases with increasing temperature. In both cases the temperature $T_{w}$ exists above which $\theta=0$ and the grain boundary cannot exist in equilibrium with the melt. At $T_{w}$ the grain boundary wetting phase transition occurs. The temperature $T_{w}$ is $325 \pm 20^{\circ} \mathrm{C}$ for the $\mathrm{Al} / \mathrm{Sn}-3.3 \mathrm{wt} \% \mathrm{Ga}$ system and, therefore, about $300^{\circ} \mathrm{C}$ lower than for the Al/Sn system $\left(T_{w}=617^{\circ} \mathrm{C}\right)$.

\section{DISCUSSION}

Normal grain growth begins during the annealing of a cold deformed material after the end of the primary recrystallization when the deformed matrix is completely consumed by the newly formed grains with a low dislocation density. During normal grain growth the size of the individual grains is relatively uniform and the grain size distribution (i.e. the grain size $d$ normalized by the mean grain size $d_{O}$ ) does not vary with the time $t$. Normally, $d_{o} \sim t^{n}$ where $n$ should be equal to 0.5 as it follows from the dimension theory $[5,6]$. Experimentally, $n$ is known to lie between 0 and 0.5 [7-9]. In some conditions normal grain growth suddenly changes to so-called secondary recrystallization or abnormal grain growth $[10,11]$. In this case a few grains suddenly begin to grow very fast at the expense of all other recrystallized grains until these are consumed. Secondary recrystallization plays a very important role in defining the microstructure and texture of many technologically important materials [12]. In some cases, for example $\mathrm{Fe}-\mathrm{Si}$ magnetic alloys and $\mathrm{W}$ alloys for wires, the technologies have already existed for many years which permit the control of secondary recrystallization and the achievement, therefore, of the necessary magnetic and mechanical properties $[13,14]$. In these materials secondary recrystallization begins after the suppression of normal grain growth by pores or fine particles of a second phase. Such an inhibition of normal grain growth was assumed to be a necessary condition for secondary recrystallization.

In our case inhibition of normal grain growth is clearly present (see Fig.3, grain growth at $350^{\circ} \mathrm{C}$ ). Fine particles are not present in the alloy studied, and this reason for the inhibition of normal grain growth can be completely excluded. Another reason may be inhibition due to the interaction with the surface: the grain growth rate decreases (see Fig.3) when the mean grain size reaches a value (about $1.5 \mathrm{~mm}$ ) comparable with the thickness of the sample $(2.5 \mathrm{~mm})$. It is well known that the grain boundary grooves on the surface drag grain boundary migration and decrease the growth rate for grains in contact with the surface [10-13].

At the stage of normal grain growth the addition of $G$ a slows down the grain growth. The fastest grain growth occurs in the pure metal. In the alloys containing 0.001 or $0.005 \mathrm{wt} \% \mathrm{Ga}$ the grains grow slower and reach a mean grain size which is slightly below that of $5 \mathrm{~N} \mathrm{Al}$. Grain growth is clearly slowed down in Al-1 wt.\% Ga. These results are in line with the theory of impurity drag $[10,12,13]$. This theory predicts that the impurity atoms drag the grain boundary migration and, therefore, decelerate the grain growth.

Above a certain temperature the transition from normal to abnormal grain growth occurs in pure $\mathrm{Al}$ and in the Al-Ga alloys studied. This transition is very sharp if the mean grain size is plotted as function of the time. For example (see Fig. 2), the onset time of the abnormal growth lies between 20 and $24 \mathrm{~h}$. At $20 \mathrm{~h}$ the fine grained matrix is exclusively present. At $24 \mathrm{~h}$ there are practically only large abnormal grains in the sample. Special precautions were used to prepare the sample for the orientation measurements where both normal and abnormal grains are present.

The influence of temperature on the onset of abnormal grain growth is also very pronounced:

- At $350^{\circ} \mathrm{C}$ abnormal grain growth does not occur even after 720 hours;

- At $380^{\circ} \mathrm{C}$ abnormal grain growth begins after 20 hours;

- At $425^{\circ} \mathrm{C}$ abnormal grain growth begins after about 2 hours and the stage of normal grain growth practically disappears.

Therefore, a relatively narrow temperature interval exists (between 350 and $425^{\circ} \mathrm{C}$ ) where the transition from normal to abnormal grain growth can be observed. Below this interval the grains grow slowly and the grain structure remains fine. Above this narrow temperature interval the large grains appear within a very short time and it is practically impossible to conserve the fine grain structure.

The determination of the orientations of individual grains before and after the beginning of abnormal grain growth (Fig. 4) shows that about $50 \%$ of the new large grains have orientations which are completely 
different from the main (112) orientation in the fine-grained matrix. The orientations of their surfaces lie between (001) and (011). It can be supposed that these surfaces a have lower energy in comparison with (112) surfaces. Therefore, an additional driving force exists promoting the grains with (001) or (011) orientations to grow on the account of the (112) oriented fine grain matrix.

It has recently been shown that grain boundary wetting transitions in the two-phase (solid + liquid) areas of the bulk phase diagram can be closely connected with the grain boundary phase transitions (like prewetting or pre-melting) in the solid solution (one-phase) area of the phase diagram [15]. As a result a liquidlike thin film can exist on the grain boundary in equilibrium. Such thin films can completely change the properties of grain boundaries. For example, the diffusion permeability of such grain boundaries can be many times higher in comparison with "pure" ones $[15,16]$. It is well-known that Ga wets the grain boundaries in $\mathrm{Al}$ and penetrates along them very fast. In this work it is shown (Fig. 5) that the addition of only $3.3 \mathrm{wt}$. \% of $\mathrm{Ga}$ to $\mathrm{Sn}$ lowers the temperature $T_{w}$ of the grain boundary wetting transition by $300^{\circ} \mathrm{C}$. This fact indicates indirectly that $T_{w}$ in the Al-Ga system (in the absence of $\mathrm{Sn}$ ) is even lower and can coincide with the eutectic temperature $\left(T_{e}=26.6^{\circ} \mathrm{C}[1]\right)$. Therefore, it is not surprising that Ga can change grain boundary mobility and energy and, consequently, promote abnormal grain growth.

\section{Acknowledgements}

The authors are grateful to Prof. Brèchet and Dr D.Molodov for fruitful discussions. The financial support of the International Science Foundation (grant RER000) and the Russian Foundation for Fundamental Research (grant RFFI 950205487a) is acknowledged.

\section{References}

[1] Massalski T.et al. (eds.), Binary Alloy Phase Diagrams (ASM International, Materials Park, Ohio, 1990) p. 150.

[2] Shvindlerman L.S., Sursaeva V.G., Yashnikov V.P., and Faulkner R.G., Interface Sci. 2 (1994) 155-161.

[3] Randle V., Microtexture Determination and Its Applications (The Inst. of Metals, London, 1992).

[4] Straumal B., Gust W., and Molodov D. J. Phase Equilibria 15 (1994) 386-391.

[5] Lifshitz I.M., JETP 42 (1962) 1354-1360.

[6] Fradkov V.E. and Shvindlerman L.S., in Structure and Properties of Interfaces in Metals (Nauka Publishers, Moscow, 1988) pp. 213-249 (in Russian).

[7] Rhines F.R.and Craig K.R., Metall. Trans. 5 (1974) 413-418.

[8] Bolling G.F. and Winegard W.C., Acta metall. 6 (1958) 283-245.

[9] Drolet J.P. and Galibois A., Acta metall. 16 (1968) 1387-1393.

[10] Gottstein G., Rekristallisation metallischer Werkstoffe (DGM, Oberursel, 1984).

[11] Novikov V.Ju., Secondary Recrystallization (Metallurgia Publishers, Moscow, 1990).

[12] Gorelik S.S., Recrystallization of Metals and Alloys (Metallurgia Publishers, Moscow, 1978) (in Russian).

[13] Haessner F., Recrystallization of Metallic Materials (Dr.Riederer Verlag, Stuttgart, 1978).

[14] Snow D.B., Metall. Trans. A 7 (1976) 783-789.

[15] Rabkin E.I., Shvindlerman L.S., and Straumal B.B., Int. J. Mod. Phys. B 5 (1991) 2989-3028.

[16] Rabkin E.I., Semenov V.N., Shvindlerman L.S., and Straumal B.B., Acta metall. mater 39 (1991) $627-639$. 